\title{
Assessment of Mean Glandular Dose in Mammography System with Different Anode-Filter Combinations Using MCNP Code
}

\author{
Lida Gholamkar, ${ }^{1}$ Ali Asghar Mowlavi,,${ }^{2,3}{ }^{*}$ Mahdi Sadeghi, ${ }^{4}$ and Mitra Athari ${ }^{1}$ \\ ${ }^{1}$ Department of Medical Radiation Engineering, Science and Research Branch, Islamic Azad University, Tehran, Iran \\ ${ }^{2}$ Physics Department, Hakim Sabzevari University, Sabzevar, Iran \\ ${ }^{3}$ International Center for Theoretical Physics (ICTP), Associate Federation Scheme, Medical Physics Field, Trieste, Italy \\ ${ }^{4}$ Radiation Application Research School, Nuclear Science and Technology Research Institute, Tehran, Iran \\ "Corresponding author: Ali Asghar Mowlavi, Physics Department, Hakim Sabzevari University, Sabzevar, Iran. Tel: +98-5144012521, E-mail: amowlavi@hsu.ac.ir
}

Received 2016 January 22; Revised 2016 March 04; Accepted 2016 May 02.

\begin{abstract}
Background: X-ray mammography is one of the general methods for early detection of breast cancer. Since glandular tissue in the breast is sensitive to radiation and it increases the risk of cancer, the given dose to the patient is very important in mammography. objectives: The aim of this study was to determine the average absorbed dose of X-ray radiation in the glandular tissue of the breast during mammography examinations as well as investigating factors that influence the mean glandular dose (MGD). One of the precise methods for determination of MGD absorbed by the breast is Monte Carlo simulation method which is widely used to assess the dose.

Materials and Methods: We studied some different X-ray sources and exposure factors that affect the MGD. "Midi-future" digital mammography system with amorphous-selenium detector was simulated using the Monte Carlo N-particle extended (MCNPX) code. Different anode/filter combinations such as tungsten/silver (W/Ag), tungsten/rhodium (W/Rh), and rhodium/aluminium $(\mathrm{Rh} / \mathrm{Al})$ were simulated in this study. The voltage of X-ray tube ranged from $24 \mathrm{kV}$ to $32 \mathrm{kV}$ with $2 \mathrm{kV}$ intervals and the breast phantom thickness ranged from 3 to $8 \mathrm{~cm}$, and glandular fraction g varied from $10 \%$ to $100 \%$.

Results: MGD was measured for different anode/filter combinations and the effects of changing tube voltage, phantom thickness, combination and glandular breast tissue on MGD were studied. As glandular g and X-ray tube voltage increased, the breast dose increased too, and the increase of breast phantom thickness led to the decrease of MGD. The obtained results for MGD were consistent with the result of Boone et al. that was previously reported.

Conclusion: By comparing the results, we saw that $\mathrm{W} / \mathrm{Rh}$ anode/filter combination is the best choice in breast mammography imaging because of the lowest delivered dose in comparison with W/Ag and Rh/Al. Moreover, breast thickness and g value have significant effects on MGD.
\end{abstract}

Keywords: Breast phantom, Digital Mammography System, Mean Glandular Dose, MCNP Code

\section{Background}

Breast cancer is the most common type of cancer in women. It can often be treated if it is detected in time. Mammography is a good standard in the diagnosis of breast cancer. X-ray radiation is an ionizing radiation that can increase the risk of cancer in patients (1). Since glandular tissue (acinar, ductal epithelium, and associated stroma) is a radiosensitive organ (2), breast dosimetry is considered to be an important method for studying the risk of glandular tissue harm from mammography examination (3). The average dose absorbed in the central region of the breast, i.e. glandular tissue, is called mean glandular dose (MGD). International commission on radiological protection (ICRP) suggests that MGD within the breast is the best used quantity to indicate the radiation risk, which is used in the European protocol (1). Indeed, MGD is the energy deposited per unit mass of glandular tissue averaged over all the glandular tissue in the breast (3). The breast tissues are assumed to be homogeneous tissues in the assessment of MGD. The energy absorbed in the adipose tissue and skin is not included in the calculation of MGD because the carcinogenic risk in them is considered to be minimal (3).

According to the ALARA principle, the total absorbed dose in the glandular tissue should be kept as low as possible (4). Also, the international atomic energy agency (IAEA) recommends that the MGD value must be less than $3.0 \mathrm{mGy}$ for $42 \mathrm{~mm}$ of compressed breast consisting of $50 \%$ glandular and $50 \%$ adipose tissues (5).

We assumed that the condition of electron equilibrium is satisfied in the breast tissue because the energy 
of photonic spectrum is low. Therefore, it is true to assume that the absorbed dose is the same and equal to kerma (4). The factors that affect MGD calculations are radiation transport simulation code, cross section data, Xray spectra, half value layer (HVL), mAs, skin and adipose layer thicknesses, tissue composition, breast shape and size, thickness of breast support, backscattering materials, and presence and absence of a compression plate (3). In the past decades, molybdenum/molybdenum (Mo/Mo) anode/filter combination was generally used in conventional mammography (6).

\section{Objectives}

In this study, we assessed MGD for W/Ag, W/Rh and $\mathrm{Rh} / \mathrm{Al}$ anode/filters that were used in modern mammography systems. In mammography, the dose is high for women who have large breasts, and a shift to harder Xray spectra is effective; that is why tungsten anode is under new investigations (2). A study conducted by Dance et al. showed that if $\mathrm{W} / \mathrm{Rh}$ combination was used instead of $\mathrm{Mo} / \mathrm{Mo}$, the mean glandular dose to the breast tissue could be reduced up to $50 \%$ (7). This study also conveyed that the dose of Mo/Mo anode/filter was high only for breast thickness of $2 \mathrm{~cm}$. For all other thicknesses and glandularities, each of the alternative anode/filter combinations $\mathrm{Mo} / \mathrm{Rh}, \mathrm{W} / \mathrm{Rh}, \mathrm{Rh} / \mathrm{Rh}$ and $\mathrm{Rh} / \mathrm{Al}$ had a lower dose for the same contrast-to-noise ratio (CNR). Then they suggested that for thicknesses of $4 \mathrm{~cm}$ to $6 \mathrm{~cm}, \mathrm{~W} / \mathrm{Rh}$ was preferred (7). Dance et al. calculated MGD with Monte Carlo simulation and their work is the basis of calculating MGD in breast dosimetry protocols (8). The Monte Carlo technique is an alternative method for a precise simulation of radiation transport in a breast model and is an accurate determination of the mean glandular dose absorbed in the breast (3).

For detection of micro calcifications and tumors, Bernhardt et al. calculated MGD for different breast thicknesses and compositions, anode/filter combinations, different filter thicknesses, and different tube voltages. They have shown that for all breast thicknesses and compositions, the $\mathrm{W} / \mathrm{Rh}$ target/filter combination is the best choice in digital mammography (9). Baldelli et al. said that by using a $\mathrm{W} / \mathrm{Rh}$ target/filter, they achieved the same CNR with a lower dose than using Mo/Mo or Mo/Rh. They showed that the result is valid for all breast thicknesses, but it is more significant for the breasts with high thicknesses (6).

\section{Materials and Methods}

We studied factors that have effects on calculating MGD during mammography examinations with X-ray radi- ation in the glandular tissue of the breast. We used MCNPX Monte Carlo simulation code.

In mammography, low energy X-ray is used for breast imaging. In this study, the MCNPX code, version2.6.0 (10) was used for photon transport simulation to calculate the X-ray spectra and to estimate MGDs. We calculated MGDs in 2 steps. First, we simulated X-ray tube of full field digital mammography system "Midi-Future" (Brestige, Korea) with simple geometry and achieved X-ray spectra of different anode/filters like $\mathrm{W} / \mathrm{Rh}, \mathrm{W} / \mathrm{Ag}, \mathrm{Rh} / \mathrm{Al}$ in the tube voltage range of 24 to $32 \mathrm{kV}$ with $2 \mathrm{kV}$ intervals. According to the simple configuration displayed in Figure 1, mono energetic electrons collide to the anode and X-ray spectra will be produced. The spectra for Rh, Ag and Al filters with thicknesses of $50 \mu \mathrm{m}, 75 \mu \mathrm{m}$ and $1 \mathrm{~mm}$, respectively, are shown in Figure 2 .

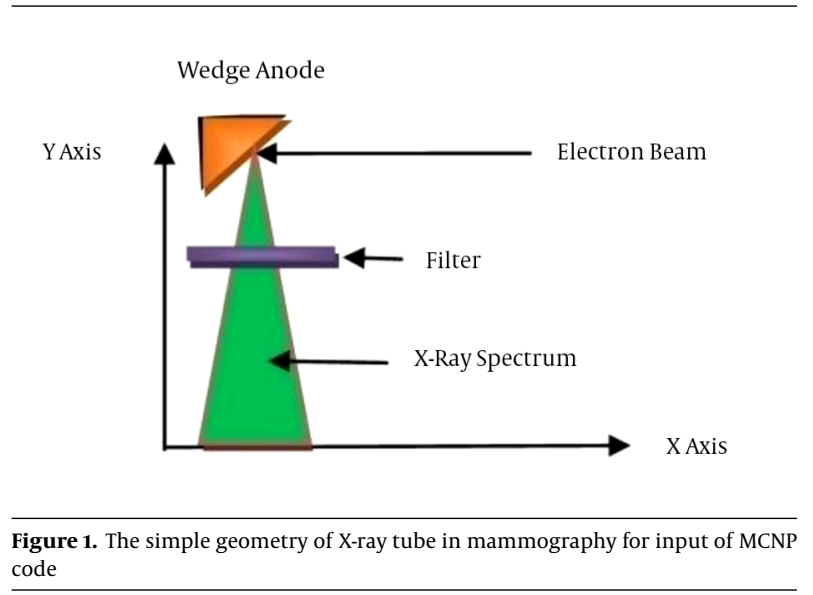

In the second step of simulation, the obtained X-ray spectra were set as a source in the input file for calculating MGDs. We considered a compressed breast phantom between two plates in the mammography system, i.e. compression pedal and support plate of the breast. The X-ray source was $64 \mathrm{~cm}$ above the top surface of the breast phantom.

\subsection{The Phantom}

The compressed breast phantom in the cranio-caudal projection was a semicircular cylinder with $8.6 \mathrm{~cm}$ of radius and between 3 and $8 \mathrm{~cm}$ of thickness. According to Figure 3, it includes three nested semi-cylinder skin, adipose and glandular tissues. Glandular-adipose region in the central part of the breast phantom was a semi-cylinder with $8 \mathrm{~cm}$ radius, surrounded by $0.5 \mathrm{~cm}$ of adipose tissue layer. A skin layer with a thickness of $1 \mathrm{~mm}$ was surrounding the adipose tissue. Elemental compositions and densities of the glandular and adipose tissues were used according to Hammerstein et al. data (11) and international com- 

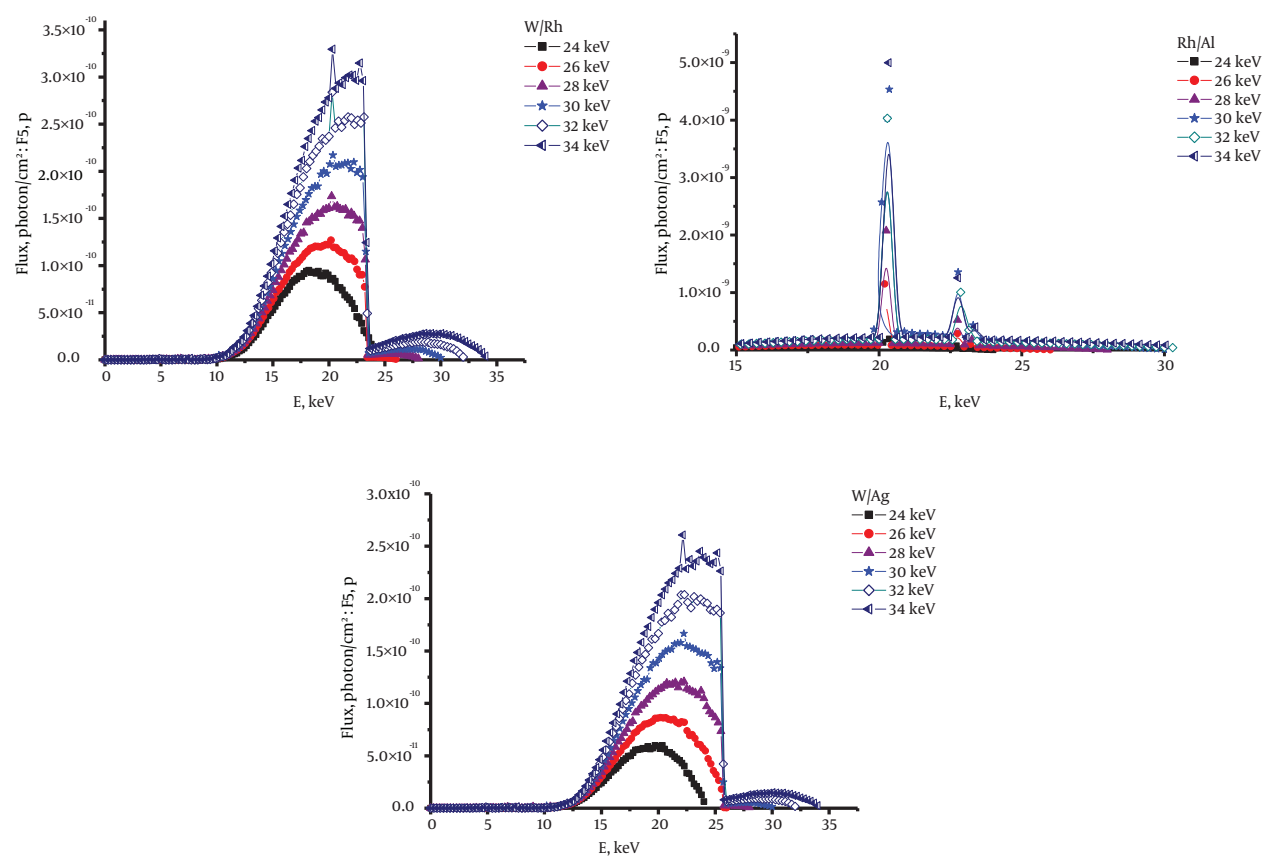

Figure 2. X-ray spectra of W/Rh, Rh/Al and W/Ag, with 24 to $34 \mathrm{kV}$ accelerated electrons, produced by MCNPX 2.6.0 (W/Rh, Tungsten/Rhodium; Rh/Al, Rhodium/ Aluminium;(W/Ag, Tungsten/ Silver)

mission on radiation units and measurements (ICRU) Report No. 44 (12).

The mass energy absorption coefficients of gland and adipose tissue in different energies that were used in the calculation of MGD were taken from the National institute of standards and technology (NIST) database and XCOM photon cross section compilations $(13,14)$.

The support plate material is a carbon fiber with 1.45 $\mathrm{g} / \mathrm{cm}^{3}$ density and $1 \mathrm{~mm}$ thickness and compression pedal material is a polycarbonate with $1.2 \mathrm{~g} / \mathrm{cm}^{3}$ density and 1.2 mm thickness (5). Using F6: P tally (energy deposition averaged over a specific volume as a geometry cell) in MCNPX code, we investigated the absorbed energy in unit mass of breast tissue, $\mathrm{MeV} / \mathrm{g}$. As mentioned before, the breast tissue was considered as a homogeneous mixture of gland and adipose tissues. Therefore, for each glandular $\mathrm{g}$ ( $0 \%$ to $100 \%$ ), we calculated the weight fraction of all the elements in the breast tissue with the help of a Fortran Power Station (version 4) program and data of Hammerstein et al. (11).

\subsection{Mean Glandular Dose}

Using the following Equations (Equations 1-3) we can calculate the mean glandular dose. The density of the breast tissue based on glandular $\mathrm{g}$ is given by:

$\rho=\frac{\rho_{a} \rho_{g}}{g \rho_{a}+(1-g) \rho g}$
Where $\rho_{\mathrm{a}}$ and $\rho_{\mathrm{g}}$ are the densities of adipose and glandular tissues, respectively $\left(\rho_{\mathrm{a}}=1.04 \mathrm{~g} / \mathrm{cm}^{3}\right.$ and $\rho_{\mathrm{g}}=0.93$ $\mathrm{g} / \mathrm{cm}^{3}$ ) and the glandular $\mathrm{g}$ is the ratio of the glandular tissue to the breast tissue and 1-g is the ratio of the adipose tissue to the breast tissue by weight (12). The portion of the absorbed energy in the glandular tissue of the breast, G, due to the glandular $\mathrm{g}$ is:

$G(E)=\frac{g \times\left(\frac{\mu_{e n}}{\rho}\right) g}{g \times\left(\frac{\mu_{e n}}{\rho}\right) g+(1-g)\left(\frac{\mu_{e n}}{\rho}\right) a}$

Where $\left(\mu_{\mathrm{en}} / \rho\right) \mathrm{g}$ and $\left(\mu_{\mathrm{en}} / \rho\right) \mathrm{a}$ are the photon mass absorption coefficients of the glandular and the adipose tissues, respectively (15).

MGD can be obtained from the absorbed dose distribution $\mathrm{D}(\mathrm{E})$ as the output of $\mathrm{F}_{6}$ tally in energy bins in the breast tissue:

$M G D=\int D(E) \times G(E) d E$

The integral of $\mathrm{D}(\mathrm{E})$ is the mean glandular dose (MGD) to the breast tissue (1). To compare with other works, the MGD values are expressed in units of mGy.

\subsection{MCNP Code}

MCNP is a general purpose Monte Carlo code that can be used for neutron, photon and electron or coupled neutron/photon/electron transport in a large range of energy. 

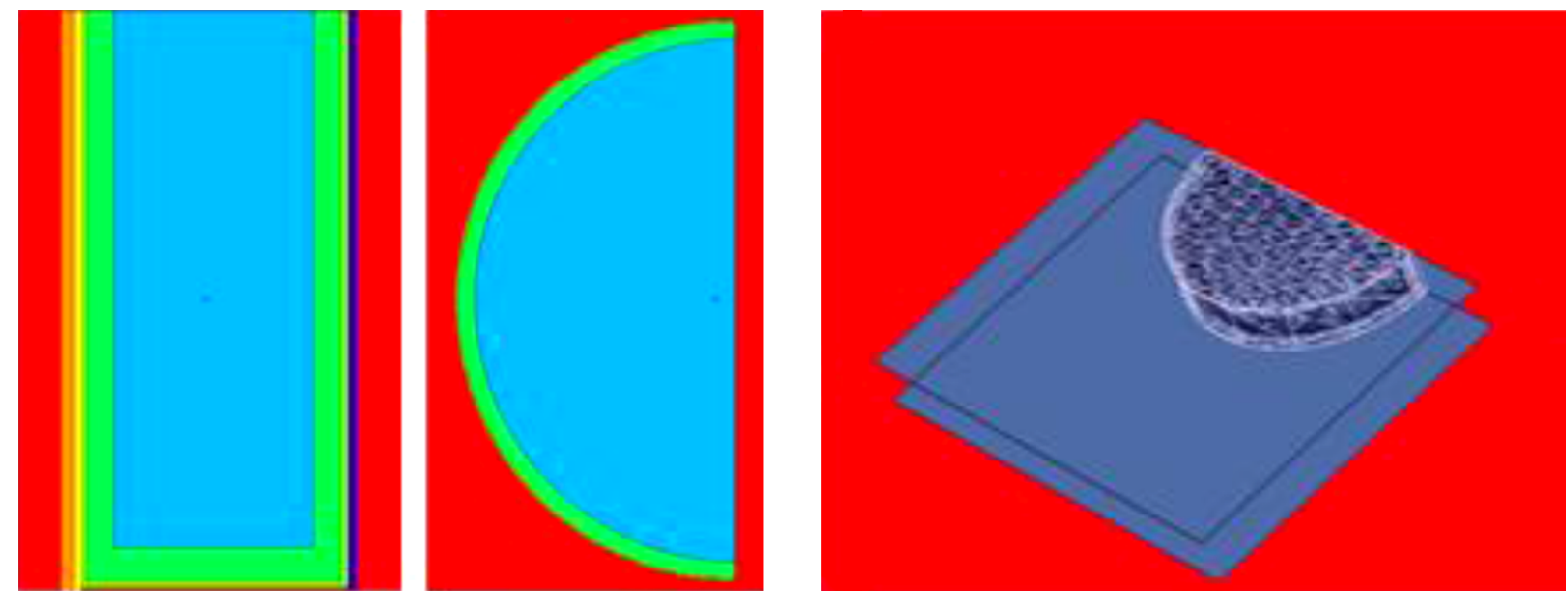

Figure 3. Simulated breast phantom in the mammography system with visual MCNP code (XY and XZ view)

In this study, we used version MCNPX 2.6.0. In MCNP code, three-dimensional coordinates are used to define geometric cell, surface and interaction environment. MCNPX 2.6.0 is the next generation in the series of Monte Carlo transport codes that began at Los Alamos National Laboratory in 2008 after the development of MCNPX2.5.0 and MCNP4C. Improvement of physics simulation models, extension of neutron, proton, and photonuclear libraries to $150 \mathrm{MeV}$ and formulation of new variance-reduction and data-analysis techniques are the most considerable characteristics of this code (10).

\subsection{XCOM Database}

XCOM web program database can be used to calculate total attenuation coefficients, for any element, compound or mixture $(Z \leq 100)$, as well as photon cross sections for incoherent scattering, coherent scattering, photoelectric absorption and pair production at energies from $1 \mathrm{keV}$ to $100 \mathrm{GeV}$. Tables in XCOM program include cross sections for many elements. Photon cross sections for compounds or mixtures can be obtained accurately as a weighted summation of the cross sections for the atomic constituents except for energies close to absorption edges.

The sum of the interaction coefficients for the individual processes is equal to the total attenuation coefficient. The weighting factors, which are the fractions by weight of the components in the compounds, are calculated by XCOM from the chemical formula that the user entered (14).

\section{Results}

In this investigation, we calculated MGDs for W/Rh, W/Ag and Rh/Al anode-filter combinations using MC-
NPX2.6.0 code and studied the effects of varying breast phantom thickness, glandularity and different X-ray tube voltages on MGD value. In all simulating results, statistical error was less than 3\%. In Tables 1-3, calculated MGD values for 3 different anode/ filters are presented. In Figures 4 - 6, for each anode-filter combinations, we plotted MGD versus breast thickness for all the g values from 10\% to 100\% and tube voltages between 24 to $32 \mathrm{kV}$. In Figure 7, we compared our results with the findings of Boone et al. (16) for MGD versus breast thickness for W/Rh and W/Ag at 100\% glandularity. In Figure 8, for breast phantom with $4 \mathrm{~cm}$ thickness and 30\%, 50\%, 70\% and 100\% glandularity, the MGD was plotted against the tube voltage of $24 \mathrm{kV}$ to $32 \mathrm{kV}$ for W/Ag, $\mathrm{W} / \mathrm{Rh}$ and $\mathrm{Rh} / \mathrm{Al}$ target/filter combination.

\section{Discussion}

The reported results in Figures 4 - 6 show that for any breast model and any target/filter combination, more and less the curves have a similar behavior. MGD decreases as the breast thickness increases from 3 to $8 \mathrm{~cm}$ for all percentages of glandularity, as well as with increasing glandularity g, MGD increases too. Because glandular tissue of the breast is sensitive to radiation, so this part absorbs X-ray in mammography exposure and we see in figures 4 to 6 that $\mathrm{g}$ and MGD have a direct relationship i.e. with increasing $\mathrm{g}$, MGD increases too and vice versa. In addition, with increasing breast thickness, breast volume increases and the portion of absorbed X-ray in the whole breast reduces in a constant value of $g$. Therefore, MGD has an inverse relationship with breast thickness.

According to Figure 7, in general, our results are consistent with those of Boone et al. for $100 \%$ glandular, but 
Table 1. Mean Glandular Dose (MGD) for Tungsten/Rhodium (W/Rh) in Different Voltages and Glandularity g (0\% to 100\%)

\begin{tabular}{|c|c|c|c|c|c|c|c|c|c|c|c|}
\hline \multirow[b]{2}{*}{$\mathrm{d}, \mathrm{cm}$} & \multicolumn{11}{|c|}{$\mathbf{g}$} \\
\hline & $\mathbf{0} \%$ & $10 \%$ & $20 \%$ & $30 \%$ & $40 \%$ & $50 \%$ & $60 \%$ & $70 \%$ & $\mathbf{8 0} \%$ & $\mathbf{9 0} \%$ & $100 \%$ \\
\hline \multicolumn{12}{|c|}{ For W-Rh at $24 \mathbf{~ k V}$} \\
\hline 3 & 0 & 1.58 & 3.05 & 4.57 & 6.03 & 7.26 & 8.78 & 10.08 & 11.33 & 12.53 & 13.23 \\
\hline 4 & 0 & 1.36 & 2.49 & 3.72 & 4.94 & 5.96 & 7.03 & 8.0 & 8.98 & 9.88 & 10.63 \\
\hline 5 & 0 & 1.12 & 2.14 & 3.13 & 4.20 & 4.93 & 5.82 & 6.66 & 7.5 & 8.2 & 8.6 \\
\hline 6 & 0 & 0.975 & 1.85 & 2.7 & 3.52 & 4.11 & 4.79 & 5.65 & 6.25 & 6.83 & 7.26 \\
\hline 7 & 0 & 0.87 & 1.64 & 2.36 & 3.08 & 3.5 & 4.11 & 4.96 & 5.47 & 5.92 & 6.4 \\
\hline 8 & 0 & 0.77 & 1.48 & 2.14 & 2.82 & 3.23 & 3.69 & 4.41 & 4.95 & 5.29 & 5.64 \\
\hline \multicolumn{12}{|c|}{ For W-Rh at $26 \mathbf{~ k V}$} \\
\hline 3 & 0 & 1.60 & 3.08 & 4.58 & 6.04 & 7.47 & 8.84 & 10.21 & 11.45 & 12.68 & 13.78 \\
\hline 4 & 0 & 1.37 & 2.57 & 3.76 & 4.95 & 6.04 & 7.12 & 8.11 & 9.08 & 10.01 & 10.86 \\
\hline 5 & 0 & 1.13 & 2.19 & 3.18 & 4.21 & 5.07 & 5.93 & 6.68 & 7.52 & 8.24 & 8.91 \\
\hline 6 & 0 & 0.98 & 1.9 & 2.76 & 3.58 & 4.36 & 5.08 & 5.75 & 6.41 & 7.04 & 7.58 \\
\hline 7 & 0 & 0.88 & 1.65 & 2.44 & 3.16 & 3.84 & 4.48 & 5.07 & 5.63 & 6.14 & 6.62 \\
\hline 8 & 0 & 0.78 & 1.49 & 2.19 & 2.84 & 3.42 & 4.00 & 4.5 & 5.04 & 5.48 & 5.90 \\
\hline \multicolumn{12}{|c|}{ For W-Rh at $28 \mathrm{kV}$} \\
\hline 3 & 0 & 1.61 & 3.10 & 4.60 & 6.09 & 7.52 & 8.96 & 10.3 & 11.61 & 12.76 & 13.85 \\
\hline 4 & 0 & 1.4 & 2.58 & 3.79 & 5.008 & 6.10 & 7.23 & 8.28 & 9.26 & 10.12 & 10.95 \\
\hline 5 & 0 & 1.14 & 2.20 & 3.23 & 4.22 & 5.10 & 6.06 & 7.06 & 7.68 & 8.32 & 9.07 \\
\hline 6 & 0 & 0.99 & 1.92 & 2.80 & 3.66 & 4.40 & 5.21 & 6.10 & 6.59 & 7.15 & 7.79 \\
\hline 7 & 0 & 0.89 & 1.7 & 2.48 & 3.23 & 3.90 & 4.59 & 5.35 & 5.77 & 6.34 & 6.75 \\
\hline 8 & 0 & 0.79 & 1.53 & 2.24 & 2.91 & 3.43 & 4.11 & 4.65 & 5.16 & 5.58 & 6.03 \\
\hline \multicolumn{12}{|c|}{ For W-Rh at $30 \mathrm{kV}$} \\
\hline 3 & 0 & 1.62 & 3.15 & 4.61 & 6.11 & 7.55 & 9.00 & 10.4 & 11.72 & 12.77 & 13.86 \\
\hline 4 & 0 & 1.35 & 2.62 & 3.84 & 5.04 & 6.19 & 7.34 & 8.40 & 9.42 & 10.27 & 11.32 \\
\hline 5 & 0 & 1.16 & 2.24 & 3.28 & 4.28 & 5.11 & 6.17 & 7.07 & 7.87 & 8.6 & 9.179 \\
\hline 6 & 0 & 1.016 & 1.94 & 2.84 & 3.72 & 4.42 & 5.33 & 6.11 & 6.76 & 7.33 & 7.87 \\
\hline 7 & 0 & 0.905 & 1.72 & 2.52 & 3.29 & 3.91 & 4.71 & 5.36 & 5.94 & 6.46 & 6.91 \\
\hline 8 & 0 & 0.817 & 1.58 & 2.28 & 2.97 & 3.48 & 4.22 & 4.78 & 5.32 & 5.72 & 6.19 \\
\hline \multicolumn{12}{|c|}{ For W-Rh at $32 \mathrm{kV}$} \\
\hline 3 & 0 & 1.66 & 3.16 & 4.62 & 6.33 & 7.56 & 9.00 & 10.4 & 11.74 & 12.98 & 14.28 \\
\hline 4 & 0 & 1.36 & 2.63 & 3.845 & 5.05 & 6.20 & 7.37 & 8.45 & 9.45 & 10.5 & 11.41 \\
\hline 5 & 0 & 1.17 & 2.25 & 3.29 & 4.31 & 5.28 & 6.22 & 7.08 & 7.9 & 8.7 & 9.44 \\
\hline 6 & 0 & 1.020 & 1.95 & 2.88 & 3.76 & 4.59 & 5.39 & 6.14 & 6.84 & 7.5 & 8.12 \\
\hline 7 & 0 & 0.91 & 1.76 & 2.56 & 3.32 & 4.06 & 4.8 & 5.42 & 6.03 & 6.59 & 7.16 \\
\hline 8 & 0 & 0.82 & 1.59 & 2.30 & 3.008 & 3.69 & 4.28 & 4.86 & 5.4 & 5.93 & 6.38 \\
\hline
\end{tabular}

${ }^{\mathrm{a}}$ All numbers should be multiplied by E-13, Tungsten/Rhodium (W/Rh).

our findings for MGD values are higher than the results of Boone et al. (16). Differences between the MGD values de- rived in our work and the findings of Boone et al. (16) result from different MGD calculation techniques. Because 
Table 2. Mean Glandular Dose (MGD) (mGy) for Tungsten/ Silver (W/Ag) in Different Voltages and Glandularity g (0\% to $100 \%)^{\mathrm{a}}$

\begin{tabular}{|c|c|c|c|c|c|c|c|c|c|c|c|}
\hline \multirow[b]{2}{*}{$\mathrm{d}, \mathrm{cm}$} & \multicolumn{11}{|c|}{$\mathbf{g}$} \\
\hline & $\mathbf{0} \%$ & $10 \%$ & $20 \%$ & $30 \%$ & $40 \%$ & $\mathbf{5 0} \%$ & $60 \%$ & $70 \%$ & $\mathbf{8 0} \%$ & $\mathbf{9 0} \%$ & $100 \%$ \\
\hline \multicolumn{12}{|c|}{ For W-Ag at $24 \mathbf{~ k V}$} \\
\hline 3 & 0 & 1.5 & 3.05 & 4.64 & 6.05 & 7.40 & 9.07 & 10.39 & 11.76 & 12.68 & 13.76 \\
\hline 4 & 0 & 1.41 & 2.55 & 3.87 & 5 & 6.22 & 7.32 & 8.36 & 9.37 & 10.1 & 11.2 \\
\hline 6 & 0 & 1.01 & 1.93 & 2.84 & 3.6 & 4.35 & 5.26 & 5.96 & 6.64 & 7.26 & 7.71 \\
\hline 7 & 0 & 0.89 & 1.68 & 2.52 & 3.1 & 3.74 & 4.66 & 5.28 & 5.81 & 6.23 & 6.61 \\
\hline 8 & 0 & 0.80 & 1.55 & 2.27 & 2.82 & 3.42 & 4.14 & 4.68 & 5.28 & 5.66 & 6.03 \\
\hline \multicolumn{12}{|c|}{ For W-Ag at 26 kV } \\
\hline 3 & 0 & 1.55 & 3.08 & 4.67 & 6.07 & 7.5 & 9.13 & 10.4 & 11.93 & 13.28 & 14.57 \\
\hline 4 & 0 & 1.35 & 2.6 & 3.915 & 5.168 & 6.36 & 7.52 & 8.64 & 9.7 & 10.72 & 11.7 \\
\hline 5 & 0 & 1.15 & 2.28 & 3.36 & 4.41 & 5.35 & 6.36 & 7.28 & 8.14 & 8.96 & 9.73 \\
\hline 6 & 0 & 1.04 & 2.01 & 2.94 & 3.85 & 4.6 & 5.52 & 6.28 & 7.008 & 7.7 & 8.35 \\
\hline 7 & 0 & 0.93 & 1.79 & 2.6 & 3.42 & 4.16 & 4.88 & 5.55 & 6.13 & 6.77 & 7.4 \\
\hline 8 & 0 & 0.84 & 1.61 & 2.368 & 3.088 & 3.7 & 4.38 & 4.99 & 5.55 & 6.06 & 6.56 \\
\hline \multicolumn{12}{|c|}{ For W-Ag at $28 \mathbf{~ k V}$} \\
\hline 3 & 0 & 1.56 & 3.10 & 4.67 & 6.13 & 7.51 & 9.14 & 10.45 & 11.98 & 13.38 & 14.67 \\
\hline 4 & 0 & 1.36 & 2.64 & 3.92 & 5.17 & 6.4 & 7.59 & 8.72 & 9.80 & 10.78 & 11.8 \\
\hline 5 & 0 & 1.16 & 2.3 & 3.39 & 4.44 & 5.34 & 6.46 & 7.39 & 8.27 & 9.12 & 9.92 \\
\hline 6 & 0 & 1.045 & 2.015 & 2.98 & 3.89 & 4.68 & 5.62 & 6.41 & 7.17 & 7.86 & 8.54 \\
\hline \multicolumn{12}{|c|}{ For W-Ag at $30 \mathrm{kV}$} \\
\hline 3 & 0 & 1.58 & 3.12 & 4.77 & 6.14 & 7.64 & 9.15 & 10.57 & 12 & 13.39 & 14.75 \\
\hline 4 & 0 & 1.371 & 2.65 & 3.93 & 5.18 & 6.42 & 7.64 & 8.75 & 9.92 & 10.98 & 12.048 \\
\hline 5 & 0 & 1.18 & 2.33 & 3.40 & 4.45 & 5.56 & 6.53 & 7.52 & 8.4 & 9.28 & 10.128 \\
\hline 6 & 0 & 1.05 & 2.05 & 3.008 & 3.95 & 4.84 & 5.79 & 6.53 & 7.3 & 8.03 & 8.70 \\
\hline 7 & 0 & 0.95 & 1.85 & 2.704 & 3.53 & 4.3 & 5.08 & 5.8 & 6.46 & 7.08 & 7.73 \\
\hline 8 & 0 & 0.867 & 1.68 & 2.44 & 3.2 & 3.9 & 4.57 & 5.22 & 5.82 & 6.39 & 6.93 \\
\hline \multicolumn{12}{|c|}{ For W-Ag at $32 \mathrm{kV}$} \\
\hline $3 \mathrm{~cm}$ & 0 & 1.59 & 3.2 & 4.80 & 6.15 & 7.65 & 9.16 & 10.6 & 12.03 & 13.4 & 14.79 \\
\hline $4 \mathrm{~cm}$ & 0 & 1.38 & 2.68 & 3.91 & 5.2 & 6.43 & 7.65 & 8.81 & 10.01 & 10.99 & 12.06 \\
\hline $5 \mathrm{~cm}$ & 0 & 1.2 & 2.35 & 3.4 & 4.5 & 5.58 & 6.56 & 7.55 & 8.42 & 9.30 & 10.16 \\
\hline $6 \mathrm{~cm}$ & 0 & 1.06 & 2.08 & 3.008 & 3.95 & 4.86 & 5.79 & 6.56 & 7.34 & 7.94 & 8.75 \\
\hline $7 \mathrm{~cm}$ & 0 & 0.96 & 1.86 & 2.75 & 3.54 & 4.34 & 5.10 & 5.82 & 6.51 & 7.09 & 7.76 \\
\hline $8 \mathrm{~cm}$ & 0 & 0.87 & 1.69 & 2.45 & 3.21 & 4.01 & 4.60 & 5.24 & 5.85 & 6.4 & 6.97 \\
\hline
\end{tabular}

${ }^{\text {a } A l l ~ n u m b e r s ~ s h o u l d ~ M G D: ~ b e ~ m u l t i p l i e d ~ b y ~ E-13 . ~}$

of the exact transport of photons and electrons in MCNPX code, it is a precise code and it can be said that our results are more accurate than those of Boone et al. For W/Ag and $\mathrm{W} / \mathrm{Rh}$ combination, by increasing phantom thickness, the 
Table 3. Mean Glandular Dose (MGD) (mGy) for Rhodium/Aluminium (Rh/Al) in Different Voltages and Glandularity g (0\% to $100 \%)^{\mathrm{a}}$

\begin{tabular}{|c|c|c|c|c|c|c|c|c|c|c|c|}
\hline \multirow[b]{2}{*}{$\mathrm{d}, \mathrm{cm}$} & \multicolumn{11}{|c|}{$\mathbf{g}$} \\
\hline & $\mathbf{0} \%$ & $10 \%$ & $20 \%$ & $30 \%$ & $40 \%$ & $50 \%$ & $60 \%$ & $70 \%$ & $\mathbf{8 0} \%$ & $\mathbf{9 0} \%$ & $100 \%$ \\
\hline \multicolumn{12}{|c|}{ For Rh-Al at $24 \mathbf{~ k V}$} \\
\hline 3 & 0 & 1.59 & 3.07 & 4.56 & 6 & 7.23 & 8.75 & 10.13 & 11.3 & 12.51 & 13.2 \\
\hline 4 & 0 & 1.32 & 2.53 & 3.71 & 4.9 & 5.95 & 6.99 & 7.98 & 8.91 & 9.8 & 10.64 \\
\hline 5 & 0 & 1.16 & 2.12 & 3.13 & 4.08 & 4.8 & 5.8 & 6.6 & 7.34 & 8.04 & 8.54 \\
\hline 6 & 0 & 0.97 & 1.85 & 2.7 & 3.5 & 4.11 & 4.97 & 5.64 & 6.25 & 6.83 & 7.26 \\
\hline 7 & 0 & 0.85 & 1.63 & 2.38 & 3.08 & 3.61 & 4.36 & 4.94 & 5.47 & 5.96 & 6.35 \\
\hline 8 & 0 & 0.71 & 1.47 & 2.14 & 2.76 & 3.23 & 3.9 & 4.41 & 4.88 & 5.32 & 5.66 \\
\hline \multicolumn{12}{|c|}{ For Rh-Al at $26 \mathbf{~ k V}$} \\
\hline 3 & 0 & 1.60 & 3.08 & 4.57 & 6.04 & 7.31 & 8.84 & 10.17 & 11.45 & 12.68 & 13.39 \\
\hline 4 & 0 & 1.33 & 2.56 & 3.87 & 5 & 6.27 & 7.12 & 8.45 & 9.08 & 10.01 & 10.81 \\
\hline 5 & 0 & 1.13 & 2.17 & 3.20 & 4.16 & 4.91 & 5.93 & 6.75 & 7.52 & 8.24 & 8.76 \\
\hline 6 & 0 & 0.98 & 1.88 & 2.76 & 3.58 & 4.20 & 5.08 & 5.77 & 6.41 & 7.02 & 7.45 \\
\hline 7 & 0 & 0.87 & 1.66 & 2.44 & 3.16 & 3.69 & 4.48 & 5.07 & 5.61 & 6.14 & 6.52 \\
\hline 8 & 0 & 0.78 & 1.51 & 2.19 & 2.84 & 3.31 & 4 & 4.54 & 5.02 & 5.48 & 5.82 \\
\hline \multicolumn{12}{|c|}{ For Rh-Al at $28 \mathrm{kV}$} \\
\hline 3 & 0 & 1.61 & 3.09 & 4.64 & 6.12 & 7.58 & 9.12 & 10.54 & 12 & 13.0 & 13.92 \\
\hline 4 & 0 & 1.371 & 2.64 & 3.92 & 5.14 & 6.36 & 7.52 & 8.64 & 9.77 & 10.7 & 11.65 \\
\hline 5 & 0 & 1.187 & 2.27 & 3.37 & 4.41 & 5.34 & 6.38 & 7.29 & 8.24 & 9.008 & 9.55 \\
\hline 6 & 0 & 1.046 & 2.01 & 2.96 & 3.85 & 4.64 & 5.53 & 6.32 & 7.1 & 7.74 & 8.22 \\
\hline 7 & 0 & 0.936 & 1.79 & 2.64 & 3.44 & 4.11 & 4.89 & 5.60 & 6.27 & 6.81 & 7.24 \\
\hline 8 & 0 & 0.848 & 1.63 & 2.4 & 3.1 & 3.69 & 4.40 & 5.008 & 5.63 & 6.11 & 6.49 \\
\hline \multicolumn{12}{|c|}{ For Rh-Al at $30 \mathrm{kV}$} \\
\hline 3 & 0 & 1.62 & 3.10 & 4.65 & 6.13 & 7.64 & 9.13 & 10.57 & 12.01 & 13.0 & 14.0 \\
\hline 4 & 0 & 1.373 & 2.65 & 3.93 & 5.15 & 6.42 & 7.61 & 8.76 & 9.88 & 10.93 & 11.85 \\
\hline 5 & 0 & 1.20 & 2.30 & 3.4 & 4.38 & 5.42 & 6.51 & 7.45 & 8.36 & 9.23 & 9.79 \\
\hline 6 & 0 & 1.06 & 2.03 & 3.008 & 3.93 & 4.8 & 5.68 & 6.55 & 7.24 & 7.98 & 8.48 \\
\hline 7 & 0 & 0.95 & 1.82 & 2.68 & 3.52 & 4.32 & 5.04 & 5.77 & 6.41 & 7.05 & 7.56 \\
\hline 8 & 0 & 0.86 & 1.66 & 2.43 & 3.18 & 3.88 & 4.54 & 5.18 & 5.77 & 6.33 & 6.75 \\
\hline \multicolumn{12}{|c|}{ For Rh-Al at $32 \mathrm{kV}$} \\
\hline 3 & 0 & 1.62 & 3.10 & 4.66 & 6.14 & 7.6 & 9.13 & 10.53 & 12.01 & 13.32 & 14.13 \\
\hline 4 & 0 & 1.38 & 2.65 & 3.92 & 5.16 & 6.43 & 7.61 & 8.72 & 9.89 & 10.97 & 11.95 \\
\hline 5 & 0 & 1.21 & 2.31 & 3.41 & 4.44 & 5.45 & 6.52 & 7.48 & 8.40 & 9.28 & 9.85 \\
\hline 6 & 0 & 1.061 & 2.04 & 3.010 & 3.93 & 4.84 & 5.69 & 6.56 & 7.29 & 8.04 & 8.60 \\
\hline 7 & 0 & 0.952 & 1.83 & 2.70 & 3.53 & 4.3 & 4.97 & 5.83 & 6.48 & 7.12 & 7.57 \\
\hline 8 & 0 & 0.870 & 1.67 & 2.44 & 3.20 & 3.9 & 4.57 & 5.33 & 5.95 & 6.4 & 6.81 \\
\hline
\end{tabular}

${ }^{\mathrm{a}}$ All numbers should be multiplied by E-13.

discrepancy between the two studies increases, so that for $3 \mathrm{~cm}$ phantom thickness, the results for two different com- binations are nearly equal and for $8 \mathrm{~cm}$ thickness, the discrepancy increases. 

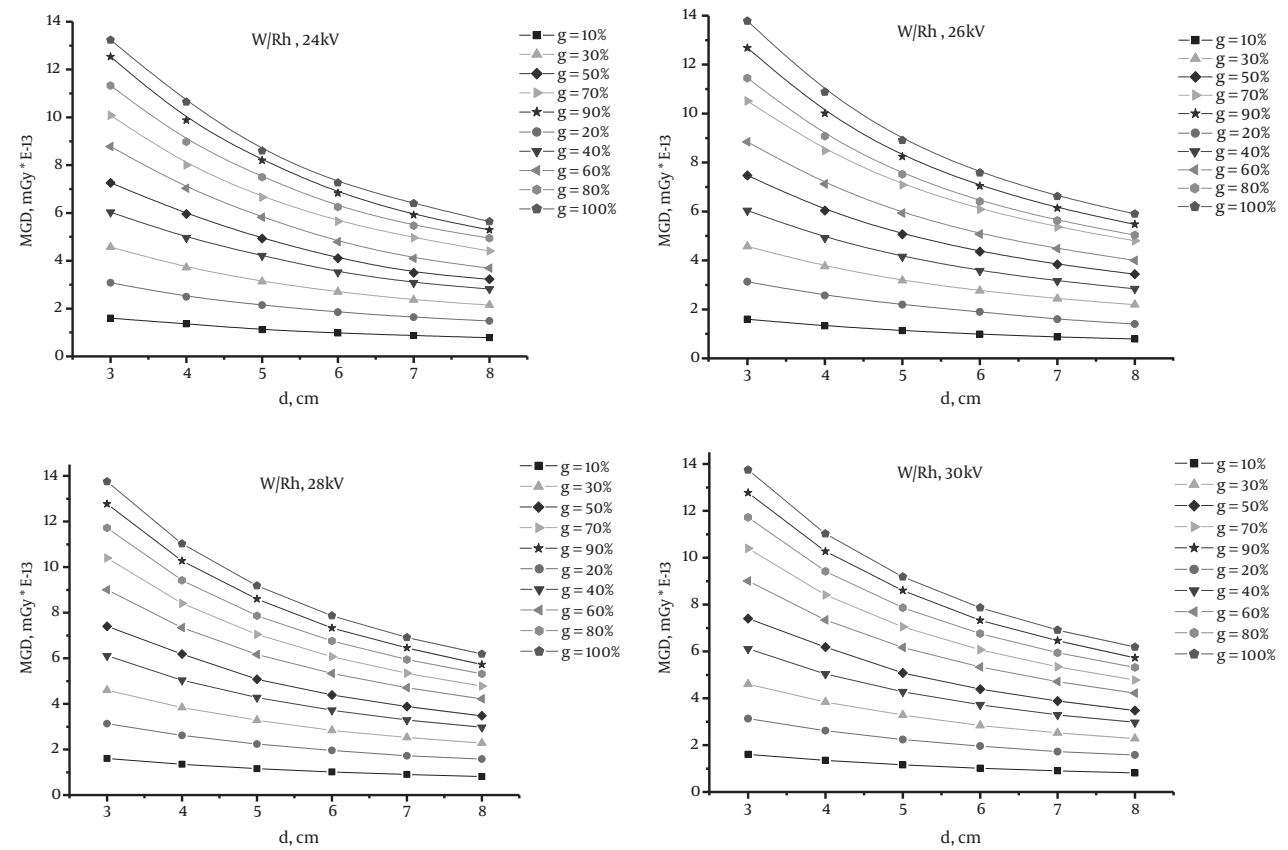

Figure 4. Mean glandular dose (MGD) values versus breast phantom thickness for $\mathrm{W} / \mathrm{Rh}$ in tube voltages $24 \mathrm{kV}$ to $30 \mathrm{kV}$ and various glandularity (g) value from $10 \%$ to $100 \%$ (W/Rh; Tungsten/Rhodium)
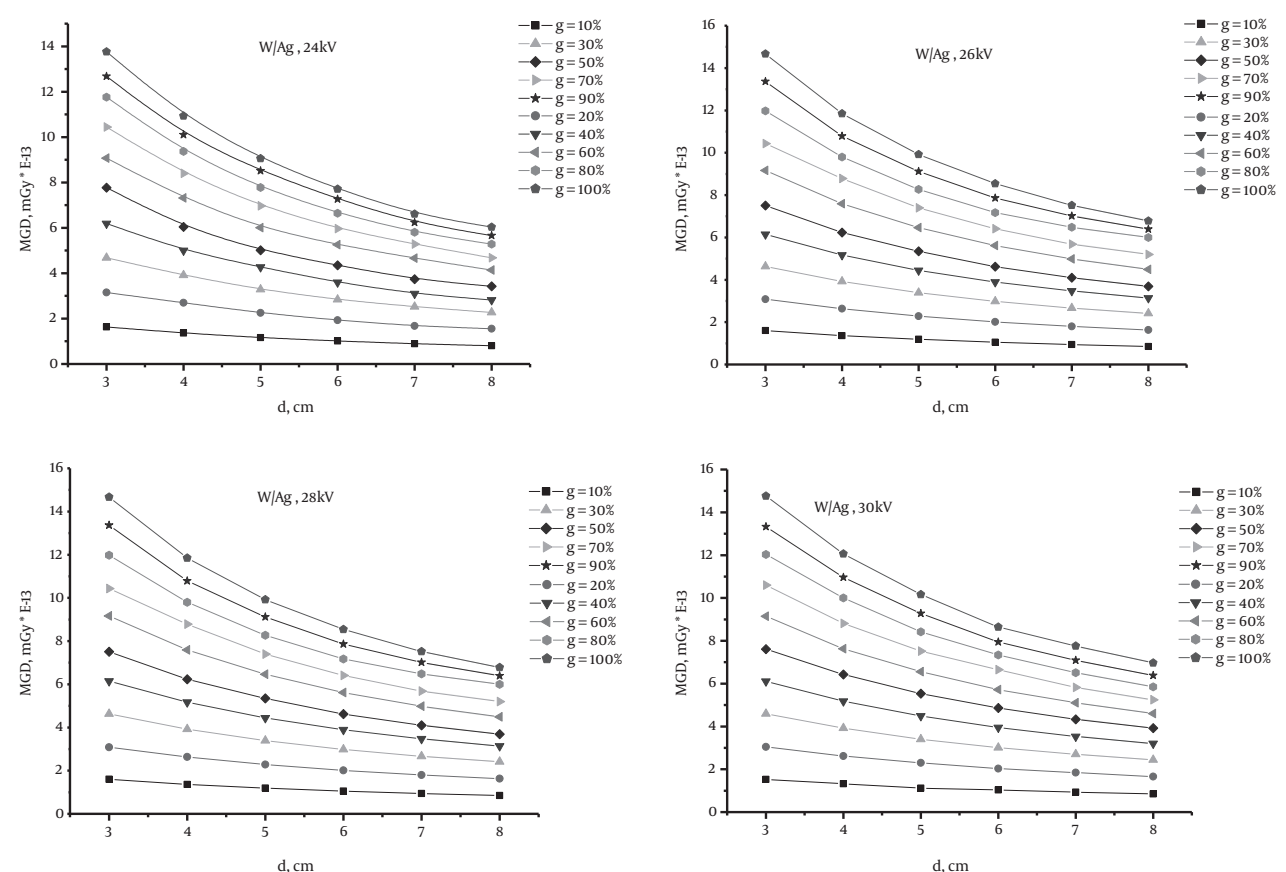

Figure 5. Mean glandular dose (MGD) values against breast phantom thickness for W/Ag in tube voltages $24 \mathrm{kV}$ to $30 \mathrm{kV}$ and various glandularity (g) value from $10 \%$ to $100 \%$ (W/Ag, Tungsten/ Silver) 

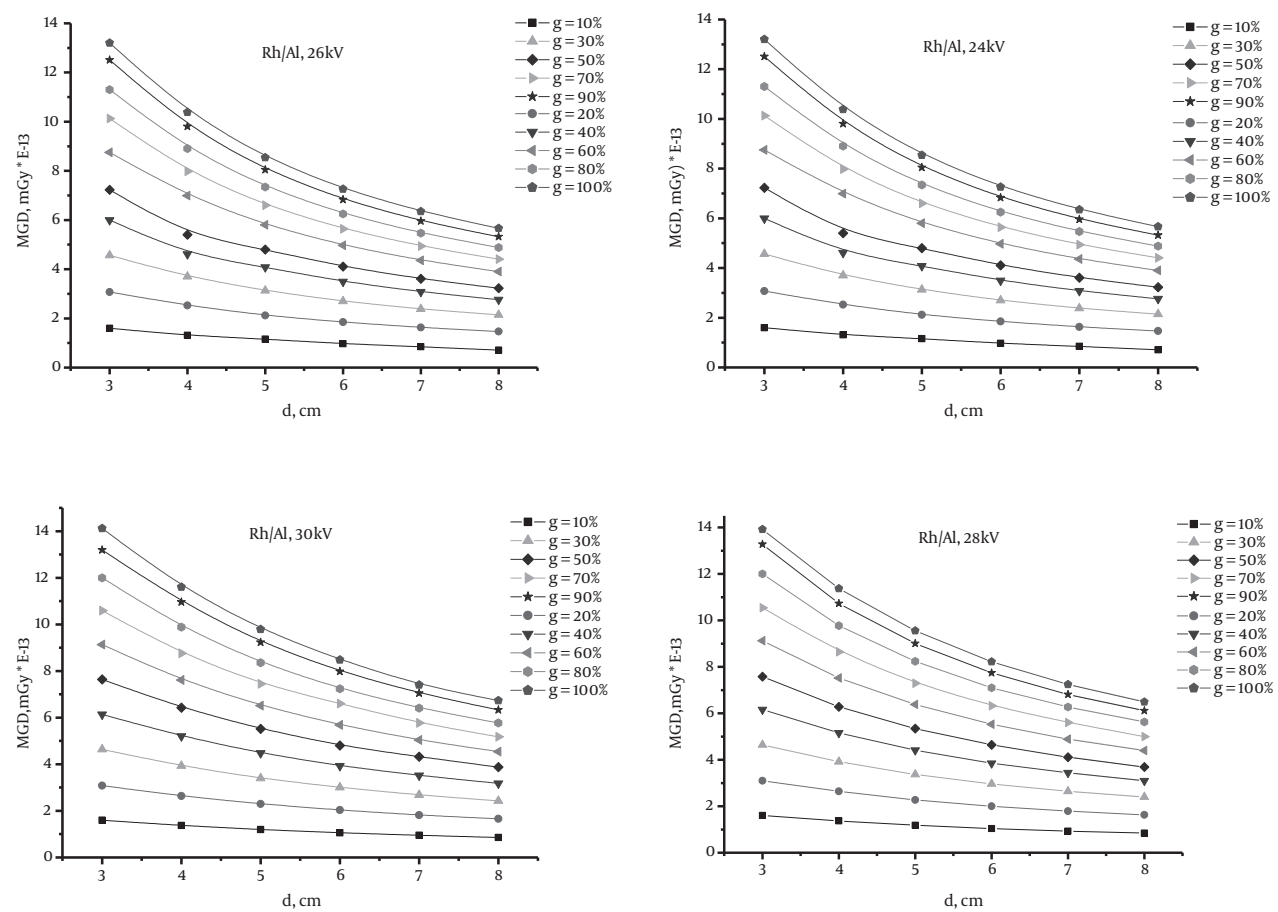

Figure 6. Mean glandular dose (MGD) values against breast phantom thickness for Rh/Al in tube voltages $24 \mathrm{kV}$ to $30 \mathrm{kV}$ and various glandularity (g) value from $10 \%$ to $100 \%$ (Rh/Al, Rhodium/Aluminium)
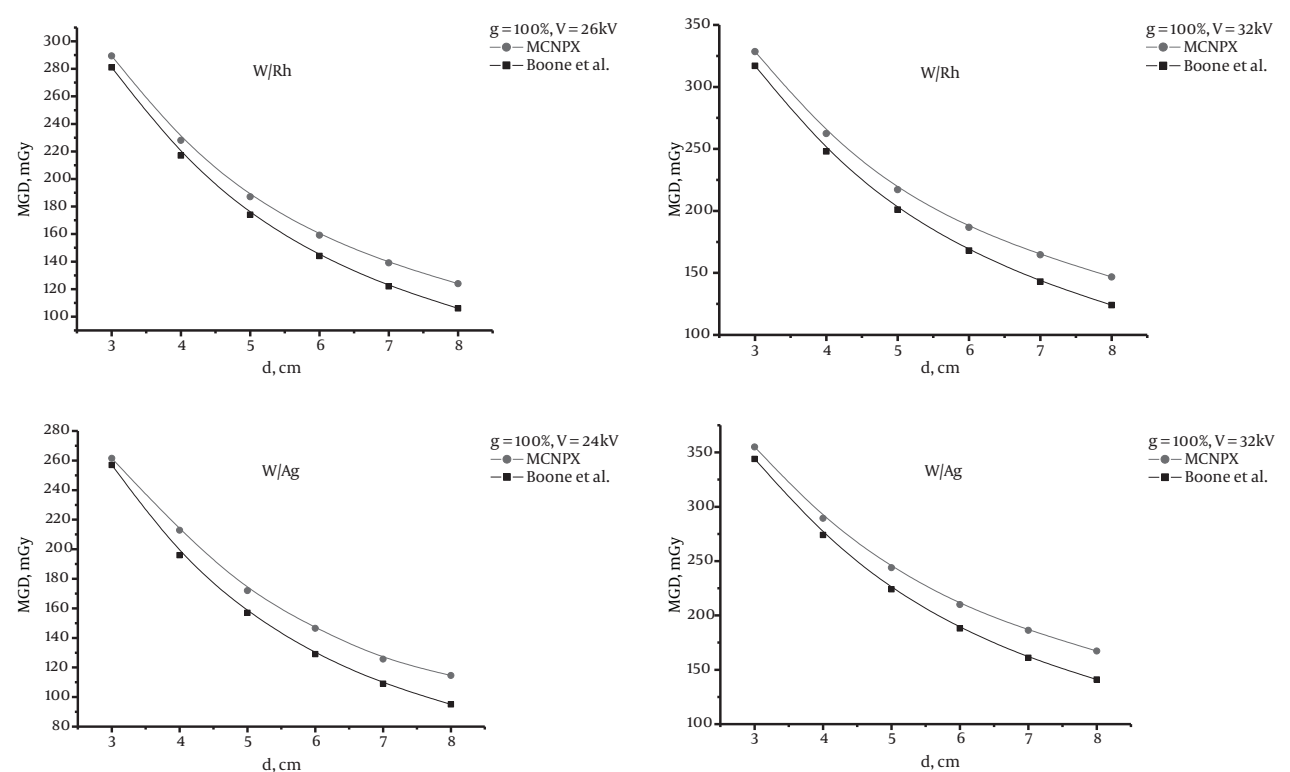

Figure 7. Comparing MGD between this study and a study conducted by Boone et al. [15] for W/Rh and W/Ag with $100 \%$ glandularity and tube voltage 24,26 and $32 \mathrm{Kv}$ (W/Rh, Tungsten/Rhodium;W/Ag, Tungsten/ Silver)

According to the curves of Figure 8, the MGD values for the combination of $\mathrm{W} / \mathrm{Rh}$ in $30 \%, 50 \%, 70 \%$ and $100 \%$ glan- 

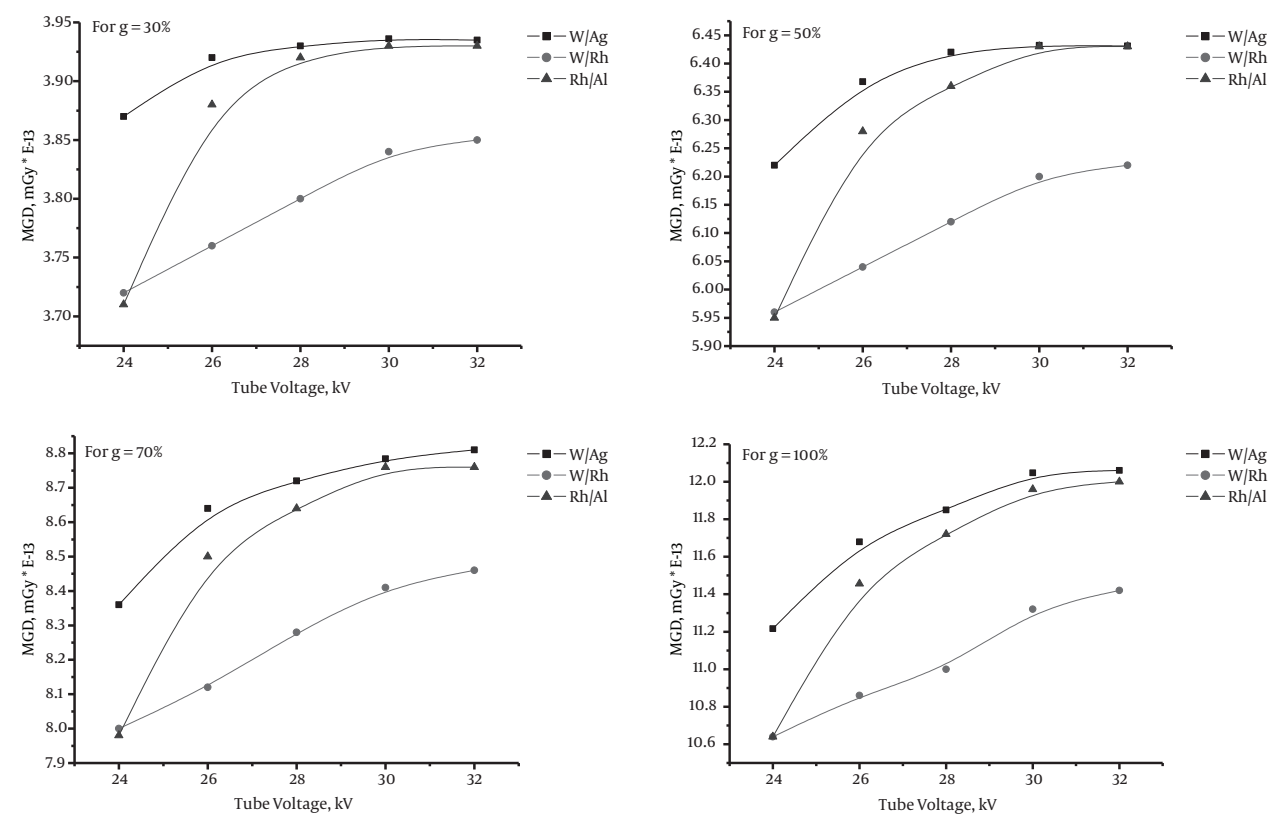

Figure 8. MGD versus tube voltage 24 to $32 \mathrm{kV}$ for $\mathrm{W} / \mathrm{Ag}, \mathrm{W} / \mathrm{Rh}$ and $\mathrm{Rh} / \mathrm{Al}$ in $30 \%, 50 \%, 70 \%$ and $100 \%$ glandularity and $4 \mathrm{~cm}$ phantom thickness $(\mathrm{W} / \mathrm{Ag}$, Tungsten/ Silver ; $\mathrm{W} / \mathrm{Rh}$, Tungsten/Rhodium; Rh/Al, Rhodium/Aluminium)

dularity are always at the lowest rate, whereas those values for the combination of W/Ag are always at the highest rate.

As it is well known, HVL depends on kVp, type of anode/filter which is calculated with regard to the thickness and composition of the breast. Since in mammography systems, the filter does not change, HVL is considered via $\mathrm{kVp}$ in MGD calculations. We changed the tube voltage in our MCNP calculations. The obtained results from MCNPX code is normalized per one particle of source. Therefore, mAs does not enter in our MGD calculations because calculate dose is done for one X-ray particle. We can multiply the dose by $\mathrm{N}$ (photon numbers) to change the normalized MGD to total dose in the breast. MCNPX calculation is independent of X-ray intensity and has the ability to change to other related quantities.

About the limitation of this study, we can say that the individual's age and race that affect the percentage of fat and glandular tissue in the breast have not been considered. Moreover, for all breast thicknesses above $8 \mathrm{~cm}$ and less than $3 \mathrm{~cm}$, all useful voltages in mammography X-ray tubes and percentage of glandular tissues have not been calculated. Also, we considered the skin thickness fixed and the shape of compact breast as fully semi-cylinder, which in fact may not be a complete semi-cylinder.

In addition, only three anode/filter combinations are examined without considering the effect of filter thickness on different mammography systems. Since the absorbed energy within the breast tissue at usual thicknesses of the breast from 3 to $8 \mathrm{~cm}$ and glandular percentages of 10 to $100 \%$ and different voltages used in mammography had not already been investigated by using MCNPX code, we found it necessary to calculate the value of MGD in a wide range of mammography tube voltages and various glandular percentages and thicknesses of the breast.

In conclusion, the results show that tissue composition, breast size and anode/filter combination do affect MGD values. Our results are consistent with current published works. Moreover, in comparison with other published data, our findings show that among the new anode/filter combinations W/Ag, W/Rh, and Rh/Al, for different compressed breast thicknesses and different breast glandularity ranging, W/Rh anode/filter is the best choice to deliver a lower dose.

In addition, we aim to calculate CNR for these anode/filter combinations and then by considering figure of merit(FOM), we will conclude that which combination will be the best choice for delivering the lowest dose against the highest image contrast in digital mammography systems.

\section{Acknowledgments}

We thank Hakim Sabzevari University and science and research branch of Islamic Azad University, Tehran. 


\section{Footnotes}

Authors' Contributions: None declared.

Financial Disclosure: None.

Funding/Support: No funding and support was received.

\section{References}

1. Ma AK, Darambara DG, Stewart A, Gunn S, Bullard E. Mean glandular dose estimation using MCNPX for a digital breast tomosynthesis system with tungsten/aluminum and tungsten/aluminum+silver x-ray anode-filter combinations. Med Phys. 2008;35(12):5278-89. doi 10.1118/1.3002310. [PubMed: 19175087].

2. Dance DR. Monte Carlo calculation of conversion factors for the estimation of mean glandular breast dose. Phys Med Biol. 1990;35(9):12119. [PubMed: 2236205]

3. Nigapruke K, Puwanich P, Phaisangittisakul N, Youngdee W. Monte Carlo simulation of average glandular dose and an investigation of influencing factors. J Radiat Res. 2010;51(4):441-8. [PubMed: 20523013].

4. Baptista M, Di Maria S, Oliveira N, Matela N, Janeiro L, Almeida P, et al. Image quality and dose assessment in digital breast tomosynthesis: A Monte Carlo study. Radiat Phys Chem. 2014;104:158-62.

5. Choi YN, Kim HJ, Park HS, Lee CL, Cho HM, Lee SW, et al. The effect of magnification on the image quality and the radiation dose in X-ray digital mammography: a Monte Carlo simulation study.J Korean Phys Soc. 2010;57(3):494-500.

6. Baldelli P, Phelan N, Egan G. Investigation of the effect of anode/filter materials on the dose and image quality of a digital mammography system based on an amorphous selenium flat panel detector.
Br J Radiol. 2010;83(988):290-5. doi: 10.1259/bjr/60404532. [PubMed: 20019173].

7. Dance DR, Thilander AK, Sandborg M, Skinner CL, Castellano IA, Carlsson GA. Influence of anode/filter material and tube potential on contrast, signal-to-noise ratio and average absorbed dose in mammography: a Monte Carlo study. Br J Radiol. 2000;73(874):1056-67. doi: 10.1259/bjr.73.874.11271898. [PubMed: 11271898].

8. Dance DR, Skinner CL, Carlsson GA. Breast dosimetry. Appl Radiat Isot. 1999;50(1):185-203. [PubMed: 10028637].

9. Bernhardt P, Mertelmeier T, Hoheisel M. X-ray spectrum optimization of full-field digital mammography: simulation and phantom study. Med Phys. 2006;33(11):4337-49. doi: 10.1118/1.2351951. [PubMed: 17153413].

10. Pelowitz D. MCNP-A general Monte Carlo N-particle transport code. Version 2.6.0 Los Alamos National Laboratory; 2008. Available from: https://mcnpx.lanl.gov.

11. Hammerstein GR, Miller DW, White DR, Masterson ME, Woodard HQ, Laughlin JS. Absorbed radiation dose in mammography. Radiology. 1979;130(2):485-91. doi: 10.1148/130.2.485. [PubMed: 760167].

12. International Commission on Radiation Units and Measurements. . Tissue substitutes in radiation dosimetry and measurement ICRU Report 44.; 1989.

13. Hubbell JH, Seltzer SM. Tables of X-ray mass attenuation coefficients and mass energy-absorption coefficients $1 \mathrm{keV}$ to $20 \mathrm{MeV}$ for elements $Z=1$ to 92 and 48 additional substances of dosimetric interest. National Inst. of Standards and Technology-PL;1995.

14. Berger M, Hubblle H. XCOM version 3.1 1999. Available from: http:// www.nist.gov/pml/data/xcom/.

15. Ma AK, Alghamdi A. Development of a realistic computational breast phantom for dosimetric simulations. Nucl Sci Thech. 2011;2:147-52.

16. Boone JM. Glandular breast dose for monoenergetic and high-energy X-ray beams: Monte Carlo assessment. Radiology. 1999;213(1):23-37. doi: 10.1148/radiology.213.1.r99oc3923. [PubMed: 10540637]. 